\title{
The researches on energy sustainability in Northern China
}

\author{
Ping Wang ${ }^{1}$, Zhiqiang Zhu ${ }^{1, *}$, and Shuang Zhang ${ }^{2}$ \\ ${ }^{1}$ Postdoctoral Workstation, Harbin Sport University, 150001 Harbin Heilongjiang, China \\ ${ }^{2}$ Scientific Research Centre, Harbin Sport University, 150001 Harbin Heilongjiang, China
}

\begin{abstract}
Energy, which accounts for two-thirds of today's greenhouse gas emissions, is the key to reducing greenhouse gas emissions and slowing global warming. In this paper, the IPCC-recommended reference approach and scenario analysis were applied to evaluate dynamic change of the energy supply and energy-related carbon dioxide emissions within the period of 2000-2025 in Northern China (NC). The results show that energy importing reliance reached $85 \%$ in 2015 and the energy structure has become more diversified in NC. In addition, the per-capita $\mathrm{CO}_{2}$ emission is significantly higher while carbon intensity is lower than those of the national average. Under the LC scenario, $\mathrm{CO}_{2}$ emissions begin to fall for the first time in 2022. Hence, if Energy-Saving and Emission-Reduction strategy and regional planning for NC are implemented fully, $\mathrm{NC}$ will achieve the national emission reduction targets in 2025 and will have a large $\mathrm{CO}_{2}$ mitigation potential in the future.
\end{abstract}

\section{Introduction}

For a century, both carbon intensity and global temperature have been on the rise. And at the same time human society has gradually come to know the consequences of climate change due to the "greenhouse effect", especially carbon dioxide emissions, making it a top international political of the day. Energy, which accounts for two-thirds of today's greenhouse-gas emissions, is at the heart of problem and so must form the core of the solution ${ }^{[1]}$. In recent years, the famous international institution such as IPCC (Intergovernment Panel on Climate Change), IEA (International Energy Agency), WB (World Bank), and the Energy Department of German, England, America issues energy report periodically to mitigate greenhouse-gas emissions and climate change. The detailed inventory of energy and future projections in light of recent economic and policy developments come from them and other institutions and countries have more and more influence on the other countries. But the regional-scale studies of energy and $\mathrm{CO}_{2}$ emissions are comparatively scarce ${ }^{[2]}$. The Northern China (NC), the China's much developed region (GDP was $22.1 \%$ of the nation's total), is now in the middle periods of industrialization with the feature of energyintensive and capital-intensive. The rapid urbanization and industrialization are still sending NC's rigid demand of energies upward. At the moment, enhancing energy security, maintaining economic growth and reducing greenhouse gas emission are becoming the major issues challenging the future of the region. Therefore, we have estimated the past and the present energy supply and $\mathrm{CO}_{2}$ emissions in $\mathrm{NC}$ by applying the IEA and IPCC recommended approaches and projected the future trends of energy demand and $\mathrm{CO}_{2}$ emissions based on China's
Medium and Long Term Energy Strategy and 2016-2025 regional planning for NC. According to the results, we have put forward a sustainable development projects for NC's future energy planning and policy making, which may provide some general insights on the effectiveness of regional-level energy conservation and GHG reduction for other regions as well.

\section{Numerical investigation}

\subsection{Estimate of energy supply}

Total primary energy supply (TPES) is made up of production, imports, exports, international marine bunkers, international aviation bunkers and stock changes. Starting with the 2009 IEA edition, international aviation bunkers is subtracted out of supply in the same way as international marine bunkers. According to energy balance table data of NC, energy supply can be calculated by the following express

$$
E=\sum_{i}\left(P_{i}+R_{i}+I_{i} \pm S_{i}\right)
$$

Where $E$ is the total primary energy supply (Mtce, million tonnes of coal equivalent), the subscript $i$ represents the various fuels, $P_{i}, R_{i}, I_{i}, E_{i}$ and $S_{i}$ denote primary production, recoveries, imports, exports and stock changes of fuel $i$ respectively.

For this analysis of the final energy consumption in $\mathrm{NC}$, the total and sectoral energy data for 2000-2015 were obtained from the Energy Balance Tables of the Yearbook database (http://www.soshoo.com.cn). The final energy consumption sector is divided into four parts:

\footnotetext{
* Corresponding author: 31777669@qq.com
} 
primary industry (such as agriculture, forestry, animal husbandry and fishery), secondary industry (such as industry and construction), tertiary industry (such as transport, storage, post and communications, wholesale, retail sales, catering trade and others) and household consumption. This study considers mainly three types of energy, including primary energy (such as coal, oil, natural gas), secondary energy (Washed coal, other coal washing, mould coal, coke, coke oven gas, other gas, gasoline, kerosene, diesel oil, fuel oil, liquefied petroleum gas, refinery gas, other petroleum products, other coking products, heat, and electricity), and other energy in the energy balance tables of NC.

\subsection{Estimation of $\mathrm{CO}_{2}$ emissions}

Based on the energy data, the following expression provides the detailed calculation for estimating carbon dioxide $\left(\mathrm{CO}_{2}\right)$ emissions from fossil fuel combustion from NC using the IPCC-recommended Reference Approach (1996).

$$
E_{\mathrm{CO}_{2}}=\sum_{i}\left(A_{i} e_{i} c_{i} \times 10^{-3}-S_{i}\right) o_{i} M_{i}
$$

Where $\mathrm{ECO}_{2}$ is the total carbon dioxide emitted from $\mathrm{f}$ ossil fuel combustion in kilograms $\left(\mathrm{kt} \mathrm{CO}_{2}\right) ; A_{i}$ is the app arent consumption of fuel $i$ (kt or 100 million $\mathrm{m}^{3}$ for natu ral gas); $e_{i}$ is the net calorific value of fuel $i(\mathrm{TJ} / \mathrm{kt}) ; c_{i}$ is $\mathrm{t}$ he carbon emission factor of fuel $i(\mathrm{t} \mathrm{C} / \mathrm{TJ})$, $S_{i}=A_{s i} e_{i} c_{i} s_{i}$, is the carbon in products from non-en ergy uses of fossil fuels (kt C), $o_{i}$ is the carbon oxidation rate of fuel $i$, and $M$ is the molecular-to-atomic weight ra tio of $\mathrm{CO}_{2}$ to carbon (44/12). Calorific values and emissi on factors of fuels were taken from "the Revised 1996 IP CC Guidelines for National Greenhouse Gas Inventories (The IEA is still using the 1996 IPCC Guidelines)".

\subsection{Scenario analysis}

Scenarios are self-consistent story lines of how a future energy system might evolve over time under a particular set of conditions ${ }^{[3]}$. In order to analyze possible effects of series policies for energy savings and emissions mitigation, two scenarios were set up: the business as usual (BAU) scenario and the low carbon (LC) scenario. The BAU scenario assumes that the indicators of energysaving and emission reduction will be the same as before. Considering the development of new and renewable energy, the rates of energy-saving and emission reduction during 2016-2025 under the LC scenario will be increased by $0.5-1$ percentages compared with BAU. The calculation of energy consumption per unit of output value $^{[4]}$ and the major assumptions and for the BAU and LC scenarios are as follows (table 1):

$$
\begin{gathered}
\frac{E_{o}}{G_{o}}(1-m)^{t}=\frac{E_{t}}{G_{t}}=\frac{E_{t}}{G_{o}(1+n)^{t}} \\
E_{t}=E_{o}\left\lfloor(1-m)^{t} \times(1+n)^{t}\right\rfloor
\end{gathered}
$$

$$
\begin{gathered}
\frac{C_{O}}{G_{O}}\left(1-m^{\prime}\right)^{t}=\frac{C_{x}}{G_{x}}=\frac{C_{x}}{G_{O}(1+n)^{t}} \\
C_{x}=C_{O}\left\lfloor\left(1-m^{\prime}\right)^{t} \times(1+n)^{t}\right\rfloor
\end{gathered}
$$

\begin{tabular}{|c|c|c|c|c|}
\hline \multicolumn{2}{|c|}{ Key variables } & 2015 & 2020 & 2025 \\
\hline \multicolumn{2}{|c|}{ Population (millions) } & 149.91 & 157.71 & 165.92 \\
\hline \multicolumn{2}{|c|}{$\begin{array}{l}\text { Population growth rate } \\
\qquad(\%)\end{array}$} & 1.02 & 1.02 & 1.02 \\
\hline \multicolumn{2}{|c|}{ GDP per capita (yuan) } & 53434 & 82000 & 110000 \\
\hline \multicolumn{2}{|c|}{ GDP (billions of yuan) } & 8010 & 12932 & 18251 \\
\hline \multicolumn{2}{|c|}{ GDP growth rate $(\%)$} & 14 & 10 & 7 \\
\hline \multirow{2}{*}{$\begin{array}{l}\text { Saving rate of } \\
\text { energy } \\
\text { intensity }(\%)\end{array}$} & BAU & 4.0 & 4.0 & 4.0 \\
\hline & $\mathrm{LC}$ & 4.5 & 5.0 & 5.0 \\
\hline \multirow{2}{*}{$\begin{array}{l}\text { Reduction rate } \\
\text { of carbon } \\
\text { intensity }(\%)\end{array}$} & BAU & 6.5 & 6.5 & 6.5 \\
\hline & LC & 7.0 & 7.5 & 7.5 \\
\hline
\end{tabular}

Table 1. The basic assumptions for key variables in NC

\section{The energy status in NC}

\subsection{Energy supply in NC}

Based on energy balance table, the NC's energy demand rose rapidly with the continuing growth in population and economic. During 2000-2015 period, the energy supply increased from 170.51 to 436.55 Mtce, representing an annual rate of increase of $8.11 \%$. However, primary energy production was only 40.45 Mtce in 2010, an increase of $60.32 \%$ over 2000 levels but only $9.26 \%$ of NC's total supply, compared to $14.79 \%$ in 2000 . An average of nearly 85 percent of energy supply for the $2000-2015$ period must be met by imports from overseas and domestic other regions. Oil imports would be 79.73 Mtce in 2015, which was ten times as large as in 2000, as shown in figure 1.

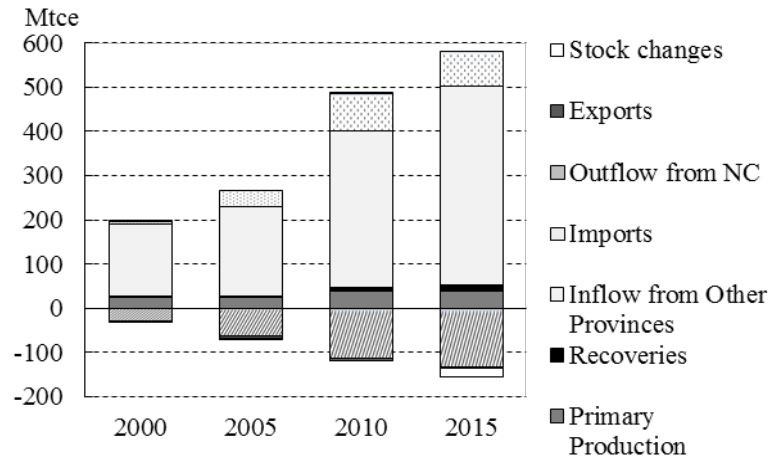

Fig.1. Energy supply by source in NC

\subsection{The final energy consumption in NC}

The analysis showed that the final energy consumption in NC rose from 169.32 Mtce in 2000, to 399.73 Mtce in 2015, accounting for 16.7 percent of total final energy consumption of China (2538.61 Mtce in 2015). In recent years, the energy structure has become more diversified in NC: the coal share has decreased from $74 \%$ in 2000 to 
$63 \%$ in 2015, and the share of crude oil, natural gas and outdoor electricity has increased $1 \%, 2 \%$ and $6 \%$ in 2015 , respectively (Figure 2). From 2000 to 2015, the energy consumption from industry contributed the largest shares, followed by household consumption and transport, as shown in Figure 3. In 2015, the total final energy consumption of the industry sector in NC reached 274.87 Mtce and accounted for 69 percent of the total. This was a substantial decline of 8 percentage points from 77 percent in 2000. Still, construction sector was the smallest energy consumer in the energy consumption. The construction sector consumed 6.82 Mtce in 2015, accounting for just 2 percent of total final energy consumption. In contrast to its small share, however, the construction sector's energy consumption grew at a leading rate of 16 percent a year on average during 20002015 period.

$\square$ Coal $\square$ Crude Oil $\square$ Natural Gas $\square$ Outdoor Electricity $\square$ Others

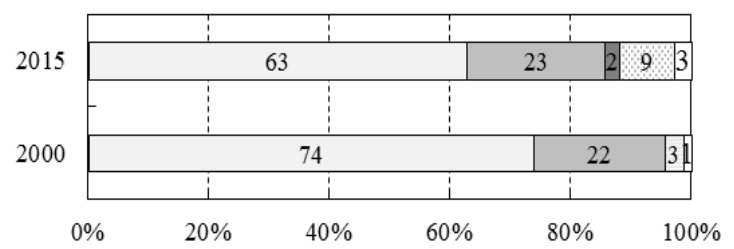

Fig.2. Shares of fuel types in final energy consumption

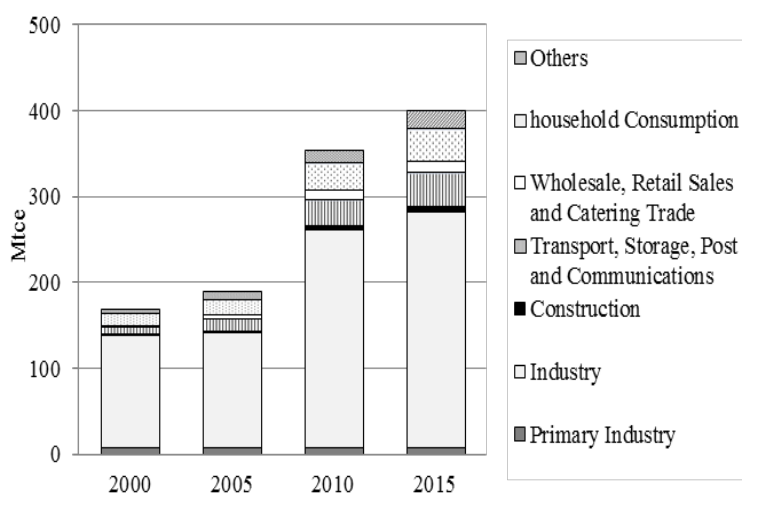

Fig.3. Final energy consumption by sector in NC

\section{3 $\mathrm{CO}_{2}$ emissions in NC}

$\mathrm{CO}_{2}$ emissions from fuel combustion in $\mathrm{NC}$ increased fro m 361.29 million tons in 2000 to 901.86 million tons in 2015 , with an average annual growth rate of $7.88 \%$. The emission of $\mathrm{CO}_{2}$ per capita in the year of 2015 was 6.3 to ns (based on resident population), which is higher than th e world average and the national average in China. In co ntrast to per-capita emissions, carbon intensity, measured as emissions per unit of GDP, was 37\% lower than that of China average and $25 \%$ higher than that of the world average level at the same period (table 2). On the other $h$ and, due to the rapid urbanization and economic develop ment of urban areas in $\mathrm{NC}, \mathrm{CO}_{2}$ emissions from urban ar eas were 623.36 million tons in 2015 , which was $69 \%$ of the total.

Table 2. Comparisons of $\mathrm{CO}_{2}$ emissions indicators, 2015

\begin{tabular}{cccccc}
\hline & World & China & India & USA & NC \\
\hline Population & 6614 & 1327 & 1123 & 306 & 144
\end{tabular}

\begin{tabular}{|c|c|c|c|c|c|}
\hline (million) & & & & & \\
\hline $\begin{array}{l}\text { Share of world } \\
\text { population (\%) }\end{array}$ & 100 & 20 & 17 & 5 & 11 \\
\hline $\begin{array}{l}\mathrm{GDP}(\$ 2016 \\
\text { trillion, } \mathrm{PPP})\end{array}$ & 67.2 & 7.6 & 3.1 & 14.1 & 1.8 \\
\hline $\begin{array}{c}\text { Share of world } \\
\text { GDP }(\%)\end{array}$ & 100 & 11 & 5 & 21 & 22 \\
\hline $\begin{array}{c}\text { Share of world } \\
\mathrm{CO}_{2} \text { emissions } \\
(\%)\end{array}$ & 100 & 21 & 5 & 20 & 15 \\
\hline $\begin{array}{c}\mathrm{CO}_{2} \text { emissions } \\
\text { per capita }(\mathrm{t})\end{array}$ & 4.4 & 4.6 & 1.2 & 18.7 & 6.3 \\
\hline $\begin{array}{c}\mathrm{CO}_{2} \text { intensity } \\
(\mathrm{kg} / \$ 2016 \\
\mathrm{ppp})\end{array}$ & 0.4 & 0.8 & 0.4 & 0.4 & 0.5 \\
\hline
\end{tabular}

Sources: IEA analysis (2017)

\section{The energy future in NC}

\subsection{Energy demand}

Based on the assumptions of socio-economic development in $\mathrm{NC}$ and the various parameters for scenarios in the calculation, the total energy demand under the BAU scenario will increase to 814.88 Mtce in 2025, which is twice as large as in 2015 (figure 4). Under the LC scenario, it will reach 722.46 Mtce in 2025, suppressing the growth of total energy demand by $0.98 \%$ annually compared to BAU. The energy intensity was 0.76 tce $/ 10,000$ yuan in 2015, and it would be 0.44 and 0.39 tce/10,000 yuan in 2025 for the BAU and LC scenarios, respectively. While the energy intensity has improved in $\mathrm{NC}$, the improvements have only been able to slow demand growth to some extent, but not to halt it, owing to rapid economic and population growth.

\section{2 $\mathrm{CO}_{2}$ emissions}

Two important turning points occurred in 2022 (figure 5): under the BAU scenario, $\mathrm{CO}_{2}$ emissions will maintain a $0.03 \%$ lower average annual growth rate during the period 2022-2025 compared to 3.54\% during 2015-2022. Due to the series of energy-saving and emissionreduction policies and measures, for the first time in 2022, $\mathrm{CO}_{2}$ emissions under the $\mathrm{LC}$ scenario will begin to fall. $\mathrm{CO}_{2}$ emissions will reach 1055.70 million tons in 2025 , suppressing the growth of total $\mathrm{CO}_{2}$ emissions by $0.95 \%$ annually compared to BAU. In per capita terms, this means 7.20 and 6.36 tons in 2025 under the BAU and LC scenarios, respectively, compared to 6.30 tons in 2015. The $\mathrm{CO}_{2}$ intensities of the economy for the BAU and LC scenarios will be reduced by $58 \%$ and $63 \%$ in 2025 compared with that in 2015, respectively. The results show that $\mathrm{NC}$ will achieve the national emission reduction targets (A 40-45\% reduction target) ${ }^{[5]}$ only when it continues its past emission reduction targets and regional plans related to energy saving and environmental protection are implemented. 


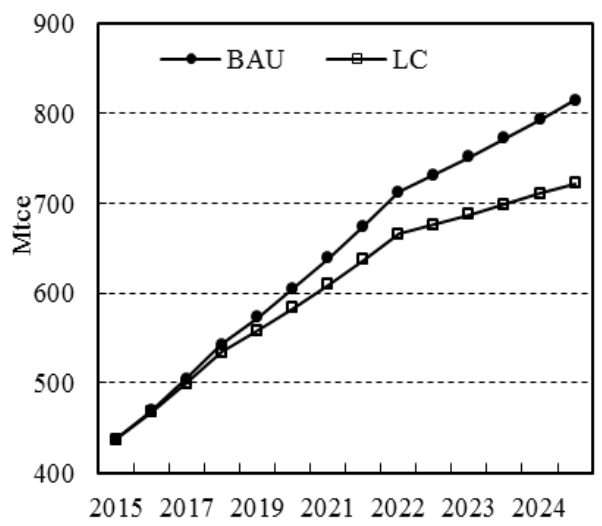

Fig.4. Trends of energy demand for two scenarios

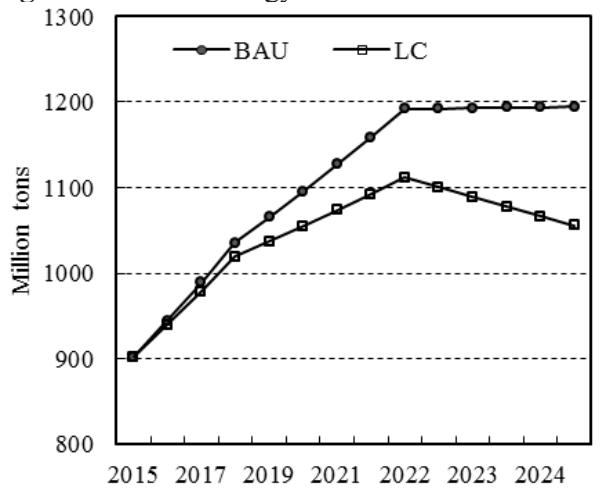

Fig.5. Trends of $\mathrm{CO}_{2}$ emissions for two Scenarios

\section{Conclusion}

In this study, the IPCC-recommended reference approach and scenario analysis were applied to $\mathrm{NC}$ to analysis dynamic change of the energy supply and energy-related $\mathrm{CO}_{2}$ emissions for 2000-2015 and project the energy demand and $\mathrm{CO}_{2}$ emissions up to 2025 under the BAU and BP scenarios. Based on the above research results, the following strategies should be undertaken to increase geographic and fuel-supply diversity, to curb the growth in energy demand and to mitigate greenhouse-gas emissions: 1) In NC, energy security has emerged as a central policy issue and is increasingly affecting regional economic and development policy. The government should ensure regional supply by diversifying the geographic sources of oil and physical supply route, strengthening energy infrastructure construction and increasing domestic production of convertional fuels. 2) We must continue recent energysaving and ejection-decreasing policies to promote the adjustment and upgrading of industrial structure, as prescribed in China's Medium and Long Term Energy Conservation Plan. Development and deployment of clean energies in a more cost-effective manner to phase in the fuel switch from coal-dominance to more shares of clean energy types such as natural gas and electricity ${ }^{[6]} .3$ ) Despite a rapid declining in carbon intensity in $\mathrm{NC}$, there is still much potential for carbon intensity to decline further, especially in some urban areas. Therefore, pursuing closer cooperation between cities and building integrated regional management platform are becoming the major tasks, which will further accelerate the spread of the information technique and ensure that energy policy challenges facing the region are addressed in a consistent manner.

\section{Acknowledgments}

Foundation item: Heilongjiang province philosophy and social science research planning project (No. 17TYH41), Heilongjiang province higher education scientific research project (No. 16G317), Project Funded by China Postdoctoral Science Foundation.

\section{References}

1. International Energy Agency. France: IEA Publications. World Energy Outlook 2017, 25 (2007)

2. P Moriarty, D Honnery. Energy Policy. What energy levels can the Earth sustain 37, 2469 (2009)

3. R Kadian, R P Dahiya, H P Garg. Energy Policy. Energy-related emissions and mitigation opportunities from the household sector in Delhi, 35 6195 (2007)

4. National Bureau of Statistics of China. Beijing: China Statistics Press, China Statistical Yearbook 2017,15 (2018)

5. M Uwasu, Y Jiang, H P Garg. Sustain.Sci. On the Chinese carbon reduction target ,23,1553 (2015)

6. J W Hannah, M O Hari. Ecol.Law.Quar. Regional Energy Governance and U.S. Carbon Emissions. 43, 22 (2016) 